\title{
Cryotherapy for retinopathy of prematurity: timing of intervention*
}

\author{
N W HINDLE \\ From the Alberta Children's Hospital, Department of Ophthalmology; the Foothills Hospital, Division of \\ Ophthalmology; and the Department of Surgery, University of Calgary, Canada
}

SUMMARY This is a retrospective study of the results of cryotherapy for retinopathy of prematurity in 30 eyes of 17 patients from November 1976 to March 1983. The report is in the language of the international classification of retinopathy of prematurity. Ten eyes were treated at stage 4 disease, seven eyes at severe or late stage 3 'plus' disease, and 13 eyes at moderate or mid-stage 3 'plus' disease. All eyes had the cryotherapy applied to the ridge and the extraretinal fibrovascular proliferation contiguous with the ridge, some with additional treatment of the avascular retina. The results show that this method of treatment must be applied before severe stage 3 'plus' disease is established in order to prevent visual disability and minimise retrolental fibroplasia. The treatment of the selected cases of progressive moderate stage 3 'plus' disease accomplished those objectives.

Severe retinopathy of prematurity (ROP) resulting in cicatricial disease or retrolental fibroplasia (RLF) is still a major cause of blindness and visual disability in infancy. ${ }^{\prime}$ All attempts at its complete medical prevention have failed. The efficacy of vitamin $E$ has been under extensive investigation, with varied reports of its effect on the incidence and severity of retinopathy of prematurity..$^{2.5}$ Total elimination of visual disability and blindness following retinopathy of prematurity is still an elusive goal.

Surgical intervention in selected severe progressive cases of retinopathy of prematurity has been recommended in the report of the Joint Committee for the Study of Retrolental Fibroplasia in Japan. ${ }^{6}$ Support for surgical intervention has been presented outside Japan. ${ }^{7-16}$ Others have concluded that treatment was of no apparent benefit ${ }^{178}$ or possibly effective in a few cases but generally not effective or perhaps deleterious. ${ }^{19}$ Although some have attempted to control their studies by treating one eye, ${ }^{84111719}$ significant evidence has not been produced to resolve the controversy.

Resolution of this dichotomy of opinion has been impaired by the inability accurately to identify those

\footnotetext{
*Presented at the American Association for Pediatric Ophthalmology and Strabismus, 4 August, 1983, Vancouver, Canada.

Correspondence to N W Hindle, MD, Department of Ophthalmology, Alberta Children's Hospital, 1820 Richmond Road, SW Calgary, Alberta, Canada T2T 5C7.
}

severe cases of retinopathy that will predictably result in visual disabling retrolental fibroplasia. In addition, the profusion of terminology and different classifications has made the comparison of results virtually impossible.

This retrospective study attempts to provide additional support for surgical intervention, with particular reference to the timing of intervention based on the appearance and progression of the acute disease.

The terminology used here is that of the international classification. ${ }^{20}$ However, during the period of this study no distinction was made between a demarcation line (stage 1) and a ridge (stage 2). Stage 3 , extraretinal fibrovascular proliferation, is subdivided as follows. Stage $3 \mathrm{a}$ has small aggregates of extraretinal fibrovascular proliferation appearing on the posterior aspect of the ridge and giving a ragged appearance to it. Stage $3 \mathrm{~b}$ has an arc of confluent extraretinal fibrovascular proliferation on the posterior aspect of the ridge, even obscuring it with extensive proliferation; stage $3 \mathrm{~b}$ may have riders or extensions posteriorly; it is pink in its progressive phase, losing its colour as involution or fibrosis occurs. Stage $3 \mathrm{c}$ is the latest and most severe manifestation and is heralded by the appearance of a sheet or membrane of small vessels extending from the internal surface of the confluent extraretinal fibrovascular proliferation, into the vitreous, perpendicular to the retina, and/or posteriorly along the retina. 
Table 1 Characteristics of 17 patients and timing of progression and treatment of retinopathy

\begin{tabular}{|c|c|c|c|c|c|c|c|c|}
\hline \multirow[t]{2}{*}{ Patient } & \multirow{2}{*}{$\begin{array}{l}\text { Year of } \\
\text { birth }\end{array}$} & \multirow{2}{*}{$\begin{array}{l}\text { Gestational } \\
\text { age (weeks) }\end{array}$} & \multirow{2}{*}{$\begin{array}{l}\text { Birth } \\
\text { weight } \\
\text { (g) }\end{array}$} & \multicolumn{5}{|c|}{ Chronological (adjusted ${ }^{*}$ ) age in days at first observation of stage } \\
\hline & & & & Eye $1 \& 2$ & 3 & $3+$ & $4-4+$ & At cryotherapy \\
\hline 1 & 76 & 30 & 1165 & $\begin{array}{l}\text { R } \\
\text { L }\end{array}$ & & $\begin{array}{l}68(-2) \\
68(-2)\end{array}$ & & $\begin{array}{l}72(2) \\
72(2)\end{array}$ \\
\hline 2 & 77 & 26 & 825 & $\begin{array}{l}\text { R } 58(-40) \\
\text { L } 58(-40)\end{array}$ & $74(-24)$ & $74(-24)$ & $\begin{array}{l}102(4) \\
102(4)\end{array}$ & $\begin{array}{l}103(5) \\
103(5)\end{array}$ \\
\hline 3 & 77 & 26 & 880 & $\begin{array}{l}\mathbf{R} \\
\mathbf{L}\end{array}$ & $\begin{array}{l}70(-28) \\
70(-28)\end{array}$ & $112(14)$ & & $\begin{array}{l}114(16) \\
\text { None }\end{array}$ \\
\hline 4 & 79 & 27 & 925 & $\begin{array}{l}\mathbf{R} \\
\mathbf{L}\end{array}$ & $\begin{array}{l}66(-25) \\
66(-25)\end{array}$ & $\begin{array}{l}73(-18) \\
73(-18)\end{array}$ & & $\begin{array}{l}91(0) \\
85(-6)\end{array}$ \\
\hline 5 & 79 & 30 & 960 & $\begin{array}{l}\mathbf{R} \\
\mathbf{L}\end{array}$ & & $\begin{array}{l}63(-7) \\
63(-7)\end{array}$ & $71(1)$ & $\begin{array}{l}66(-4) \\
66(-4)\end{array}$ \\
\hline 6 & 79 & 28 & 1140 & $\begin{array}{l}\text { R } \\
\text { L }\end{array}$ & & $\begin{array}{l}48(-36) \\
48(-36)\end{array}$ & $73(-11)$ & $\begin{array}{l}73(-11) \\
68(-16)\end{array}$ \\
\hline 7 & 79 & 27 & 755 & $\begin{array}{l}\text { R } 54(-37) \\
\text { L } 70(-21)\end{array}$ & & $\begin{array}{l}80(-11) \\
80(-11)\end{array}$ & & $\begin{array}{l}80(-11) \\
80(-11)\end{array}$ \\
\hline 8 & 80 & 29 & 1460 & $\begin{array}{l}\text { R } 40(-37) \\
\text { L } 40(-37)\end{array}$ & $\begin{array}{l}60(-17) \\
60(-17)\end{array}$ & $\begin{array}{l}71(-6) \\
71(-6)\end{array}$ & & $\begin{array}{l}71(-6) \\
71(-6)\end{array}$ \\
\hline 9 & 81 & 30 & 1600 & $\begin{array}{l}\text { R } 32(-38) \\
\text { L } 32(-38)\end{array}$ & $\begin{array}{l}45(-25) \\
45(-25)\end{array}$ & $\begin{array}{l}52(-18) \\
59(-11)\end{array}$ & $59(-11)$ & $\begin{array}{l}59(-11) \\
59(-11)\end{array}$ \\
\hline 10 & 81 & 26 & 780 & $\begin{array}{l}\mathrm{R} \\
\mathrm{L} 46(-52)\end{array}$ & & $\begin{array}{l}60(-38) \\
60(-38)\end{array}$ & $\begin{array}{l}99(1) \\
95(-3)\end{array}$ & $\begin{array}{l}101(3) \\
101(3)\end{array}$ \\
\hline 11 & 81 & 26 & 760 & $\begin{array}{l}\text { R } 69(-29) \\
\text { L } 69(-29)\end{array}$ & & $\begin{array}{l}76(-22) \\
76(-22)\end{array}$ & $\begin{array}{r}99(1) \\
101(3)\end{array}$ & $\begin{array}{l}101(3) \\
101(3)\end{array}$ \\
\hline 12 & 81 & 25 & 620 & $\begin{array}{l}\text { R } 66(-39) \\
\text { L } 52(-53)\end{array}$ & & $\begin{array}{l}80(-25) \\
82(-23)\end{array}$ & $86(-19)$ & $\begin{array}{l}86(-19) \\
\text { None }\end{array}$ \\
\hline 13 & 82 & 25 & 630 & $\begin{array}{l}\mathrm{R} \\
\mathrm{L}\end{array}$ & $65(-40)$ & $\begin{array}{l}65(-40) \\
72(-33)\end{array}$ & & $\begin{array}{l}81(-24) \\
96(-9)\end{array}$ \\
\hline 14 & 82 & 26 & 900 & $\begin{array}{l}\text { R } 33(-65) \\
\text { L } 40(-58)\end{array}$ & $\begin{array}{l}47(-51) \\
47(-51)\end{array}$ & $\begin{array}{l}67(-31) \\
57(-41)\end{array}$ & & $\begin{array}{l}69(-29) \\
69(-29)\end{array}$ \\
\hline 15 & 82 & 26 & 660 & $\begin{array}{l}\text { R } 60(-38) \\
\text { L } 53(-45)\end{array}$ & $83(-15)$ & $83(-15)$ & & $\begin{array}{l}\text { None } \\
88(-10)\end{array}$ \\
\hline 16 & 82 & 25 & 810 & $\begin{array}{l}\text { R } 44(-61) \\
\text { L } 44(-61)\end{array}$ & & $\begin{array}{l}83(-22) \\
83(-22)\end{array}$ & & $\begin{array}{l}84(-21) \\
84(-21)\end{array}$ \\
\hline 17 & 82 & 25 & 660 & $\begin{array}{l}\text { R } 45(-60) \\
\text { L } 45(-60)\end{array}$ & $\begin{array}{l}66(-39) \\
66(-39)\end{array}$ & $78(-27)$ & & $\begin{array}{l}\text { None } \\
82(-23)\end{array}$ \\
\hline Average & & 27 & 914 & $50(-45)$ & $62(-30)$ & $71(-19)$ & $89(-3)$ & $83(-8)$ \\
\hline
\end{tabular}

${ }^{*}$ Adjusted age $=[($ days since birth $)-($ days premature at birth $)]$.

In the international classification 'plus' disease means dilatation of the veins and tortuosity of the arteries in zone I. Plus disease may occur in one or more quadrants of zone I and may not be observed in the posterior pole vessels supplying sectors without serious retinopathy in zones II or III.

Cicatricial disease or retrolental fibroplasia is graded as described by Owens. ${ }^{21}$

\section{Patients and methods}

From November 1976 to March 1983, 30 eyes in 17 patients had cryotherapy for stage $3+b$ to $4+$ retinopathy of prematurity. In five years of this period 328 eyes with stage 1 to $4+$ retinopathy were identified in infants under $1500 \mathrm{~g}$ birth weight. Twenty-five eyes, or $7.5 \%$, were treated. $34 \%$ of the eyes reaching stage $3+$ and $100 \%$ of the eyes reaching $4-4+$ were treated. By birth weight group $12 \%$ of all eyes with any ROP were treated in infants under $1000 \mathrm{~g}$ at birth and $3.5 \%$ in infants 1000 to $1499 \mathrm{~g}$.

Characteristics of the 17 patients and the timing of progression of disease are shown in Table 1. Patients 1 to 8 have been included in a previous report. ${ }^{14}$

Contrary to common practice, infants at risk are currently screened and followed up by direct ophthalmoscopy through the infant gonioscopy lens (Layden infant gonioscopy lens: Ocular Instruments Inc., 12100 Northup Way, Bellevue, Washington, 98005). The examination can be conducted at any time with minimal inconvenience to the infant and the nursery staff and with atraumatic control of the ocular position. Examination of the retina to the ora serrata throughout $360^{\circ}$ is usually possible. Photographic representation of the disease can be achieved with a hand-held fundus camera through the same gonioscopy lens. Indirect ophthalmoscopy is also employed through the gonioscopy lens, and by the 
Table 2 Preoperative and early postoperative observations at 1st (second) treatment

\begin{tabular}{|c|c|c|c|c|c|}
\hline Patient & Eye & $\begin{array}{l}\text { Adjusted age } \\
\text { (days) }\end{array}$ & $\begin{array}{l}\text { Stage of } \\
\text { retinopathy }\end{array}$ & $\begin{array}{l}\text { Location* of } \\
\text { cryotherapy }\end{array}$ & Postop. comments $\dagger$ \\
\hline \multirow[t]{2}{*}{1} & $\mathbf{R}$ & 2 & $3+?$ & $1212, \mathrm{AR}$ & \\
\hline & $\mathrm{L}$ & 2 & $3+?$ & $1212, \mathrm{AR}$ & RD 0801 \\
\hline \multirow[t]{2}{*}{2} & $\mathbf{R}$ & 5 & $4+$ & $1212, \mathrm{AR}$ & RD 0711 \\
\hline & L & 5 & $4+$ & $1212, \mathrm{AR}$ & RD 0105 \\
\hline \multirow[t]{2}{*}{3} & $\mathbf{R}$ & 16 & $3+b$ & 0712, AR & \\
\hline & $\mathrm{L}$ & & $3 ?$ & none & \\
\hline \multirow[t]{2}{*}{4} & $\mathbf{R}$ & 0 & $3+b$ & 1212 & \\
\hline & $\mathrm{L}$ & $-6(1)$ & $3+b$ & $1212(10)$ & \\
\hline \multirow[t]{2}{*}{5} & $\mathbf{R}$ & $-4(1)$ & $3+c(4+)$ & $0708(1212)$ & (EFP persists) \\
\hline & $\mathrm{L}$ & $-4(1)$ & $3+c$ & $1212(?)$ & \\
\hline \multirow[t]{2}{*}{6} & $\mathbf{R}$ & -11 & $4+$ & 1212 & h \\
\hline & $\mathrm{L}$ & $-16(11)$ & $3+c$ & $1212(03,08)$ & RD 0105, h \\
\hline \multirow[t]{2}{*}{7} & $\mathbf{R}$ & $-11(-6)$ & $3+c$ & $1212(09)$ & $\mathrm{h}$ \\
\hline & $\mathrm{L}$ & $-11(-6)$ & $3+c$ & 1212 & $\mathrm{~h}$ \\
\hline \multirow[t]{2}{*}{8} & $\mathbf{R}$ & -6 & $3+b$ & 0204,0711 & $\mathbf{h}$ \\
\hline & $\mathrm{L}$ & -6 & $3+b$ & 0711 & \\
\hline \multirow[t]{2}{*}{9} & $\mathbf{R}$ & -11 & 4 & 0711 & \\
\hline & $\mathrm{L}$ & -11 & $3+b$ & 0103,0405 & RD 0305 \\
\hline \multirow[t]{2}{*}{10} & $\mathbf{R}$ & 3 & $4+$ & 1212 & Hyphaema \\
\hline & $\mathrm{L}$ & 3 & $4+$ & 1212 & Hyphaema \\
\hline \multirow[t]{2}{*}{11} & $\mathbf{R}$ & 3 & $4+$ & 0711 & RD 0710, h \\
\hline & L & 3 & $4+$ & 0205 & RD 0204, h \\
\hline \multirow[t]{2}{*}{12} & $\mathbf{R}$ & -19 & $4+$ & 0806, AR & RD 0912, h \\
\hline & L & & $3+?$ & none & \\
\hline \multirow[t]{2}{*}{13} & $\mathbf{R}$ & $-24(-9)$ & $3+c$ & $1212, \mathrm{AR}$ & $\begin{array}{l}\text { h, Cryotherapy } \\
\text { Posterior to ridge }\end{array}$ \\
\hline & $\mathrm{L}$ & -9 & $3+c$ & 0205,0711 & \\
\hline \multirow[t]{2}{*}{14} & $\mathbf{R}$ & -29 & $3+b$ & 0806 & $\mathrm{~h}$ \\
\hline & $\mathrm{L}$ & -29 & $3+b$ & 1212 & $\mathrm{~h}$ \\
\hline \multirow[t]{2}{*}{15} & $\mathbf{R}$ & & $3 b$ & none & \\
\hline & $\mathrm{L}$ & -10 & $3+b$ & 0206,0709 & h 0810 \\
\hline \multirow[t]{2}{*}{16} & $\mathbf{R}$ & -21 & $3+b$ & 0612,0304 & $\mathrm{~h}$ \\
\hline & $\mathrm{L}$ & -21 & $3+b$ & 0103,0406 & $\mathrm{~h}$ \\
\hline \multirow[t]{2}{*}{17} & $\mathbf{R}$ & & $3 b$ & none & \\
\hline & $\mathrm{L}$ & -23 & $3+c$ & 0711 & h 0711 \\
\hline
\end{tabular}

* Radial distribution in clock hours, clockwise in each eye. E.g., $0712=$ from 7 o'clock to 12 o'clock; AR = avascular retina treated.

$+\mathrm{EFP}=$ extraretinal fibrovascular proliferation; $\mathrm{h}=$ haemorrhage; $\mathrm{RD}=$ retinal detachment.

$?=$ Could not be determined from records.

usual technique, but scleral indentation is not used in the nursery. Scleral indentation is difficult for sustained viewing, distorts the disease by vascular compression, and can cause haemorrhages from the fragile extraretinal fibrovascular proliferation.

Mydriasis in patients up to six months of adjusted age is accomplished with a combination of cyclopentolate $(0.2 \%)$ and phenylephrine $(1.0 \%)$ instilled 45 minutes and 30 minutes prior to the examination. Topical proparacaine hydrochloride $(0.5 \%)$ is instilled prior to lens placement.

All at-risk infants are first examined at 4 to 5 weeks of age. The examination is repeated every two weeks until retinopathy is not anticipated or the retina is fully vascularised. If retinopathy is observed, the eyes are examined weekly. When stage 3 retinopathy appears they are examined more frequently as dictated by the severity. When regression of disease is clearly evident, the eyes are examined at dis- cretionary intervals of two weeks or more until the retinopathy is completely resolved and retinal vascularisation is complete.

The eyes were not selected for treatment on the basis of stage of disease prospectively. My attempts to determine signs of resolution, along with errors in timing of examination or treatment, resulted in the eyes being treated having reached three distinctly different stages or substages of disease.

Table 2 shows the most advanced stage of disease reached and the location of therapy. Table 3 shows a more detailed breakdown of the circumferential extent of disease, with subgradation of stage 3 disease at the time of treatment in patients 10 to 17 . The use of a proposed international classification ${ }^{22}$ and a documentation system ${ }^{23}$ since 1 December, 1981 has enabled more precise determination of qualitative and quantatative progression of disease.

Cryotherapy was applied under general anaes- 
Table 3 Location* of retinopathy and treatment at first cryotherapy, patients 10 to 17

\begin{tabular}{|c|c|c|c|c|c|c|}
\hline \multirow[t]{3}{*}{ Patient } & \multicolumn{5}{|c|}{ Location } & \multirow[t]{3}{*}{ Cryotherapy } \\
\hline & \multirow[t]{2}{*}{ Eye } & \multicolumn{4}{|c|}{ Stage of retinopathy } & \\
\hline & & $3+a$ & $3+b$ & $3+c$ & $4-4+$ & \\
\hline \multirow[t]{2}{*}{10} & $\mathbf{R}$ & & 1107 & & 0711 & 1212 \\
\hline & $\mathrm{L}$ & & & 0511 & 0205 & 1212 \\
\hline \multirow[t]{2}{*}{11} & $\mathbf{R}$ & & & & 0711 & 0711 \\
\hline & $\mathrm{L}$ & & & & 0205 & 0205 \\
\hline \multirow{2}{*}{12} & $\mathbf{R}$ & 0206 & 0809 & & 0912 & 0806 \\
\hline & L & & & & & None \\
\hline \multirow[t]{2}{*}{13} & $\vec{R}$ & 1002,0507 & 0205 & 0710 & & 1212 \\
\hline & L & & & 0105,0711 & & 0205,0711 \\
\hline \multirow[t]{2}{*}{14} & $\mathbf{R}$ & 0304,1102 & 0203,0711 & & & 0806 \\
\hline & L & 1206,0912 & 0709 & & & 1212 \\
\hline \multirow[t]{2}{*}{15} & $\mathbf{R}$ & & & & & None \\
\hline & $\mathrm{L}$ & & 0207 & & & 0206,0709 \\
\hline \multirow[t]{2}{*}{16} & $\mathbf{R}$ & & 0612 & & & 0612,0304 \\
\hline & $\mathrm{L}$ & & 1206 & & & 0103,0406 \\
\hline \multirow[t]{2}{*}{17} & $\mathbf{R}$ & & & & & None \\
\hline & $\mathrm{L}$ & $0205,0708,1011$ & 0809 & 0910 & & 0711 \\
\hline
\end{tabular}

${ }^{*}$ Radial distribution, clockwise in each eye.

thesia in an operating room. The standard retina probe was found to be too large. A cataract probe was used. Even this has been modified by placing a thinner silicone shield over the slightly curved probe leaving $2 \mathrm{~mm}$ of the $1.5 \mathrm{~mm}$ diameter tip exposed. Although the disease to be treated was usually located in zone II, we have not had to open the conjunctiva, and a sterile field is not necessary.

A previously reported histopathology clinical correlation on the eyes of patient 1 established the premise that the ridge-extraretinal fibrovascular proliferative complex should be treated.' We have mainly adhered to that principle in patients 4 to 17 . The ridge-extraretinal fibrovascular proliferative complex is straddled and the freezing is continued until the ice ball reaches the innermost surface. If there is doubt about effective freezing, a second freeze is applied. Extraretinal fibrovascular proliferations posterior to the ridge, or isolated from it, are not treated. A single continuous row of cryotherapy is applied to the arc of stage $3+b$ or worse retinopathy in addition to any stage 3 disease in continuity with it.

The treated eyes were put on $1 \%$ atropine ointment once daily and chloramphenicol-hydrocortisone ophthalmic ointment twice daily for five to seven days.

\section{Results}

Two patients developed significant bradycardia during the procedure. The anaesthetist asked for the procedure to be stopped after the left eye had been treated in patient 5 . Five days later the innermost extension of the extraretinal fibrovascular proliferation could not be frozen in some sectors of the right eye because serous detachment had developed.

During treatment of stage $3+c$ retinopathy indentation caused the intravitreal vessels to collapse, but they became visible during the freezing. As the ice ball defrosted, a small localised haemorrhage frequently appeared at the internal surface of the extraretinal fibrovascular proliferation.

In the early postoperative period a variable degree of lid oedema prevented examination for up to 48 hours. At the first possible examination 'plus' disease was markedly diminished if the extraretinal fibrovascular proliferation had been effectively treated. Iris hyperaemia disappeared as rapidly. The pupillary vascular membrane, which was frequently present at treatment, disappeared more slowly. The extraretinal fibrovascular proliferation could not usually be recognised, but small haemorrhages could frequently be seen over the cryotherapy spot. A small serous detachment sometimes occurred posterior to the cryotherapy in the most florid 'plus' cases.

In patient 10 , the only patient treated with a retina cryoprobe, the disease was entirely peripheral, and bilateral hyphaemas appeared postoperatively. They cleared spontaneously, leaving areas of iris atrophy. The unrecognised extent of the larger ice ball was probably directly responsible for this complication.

The peripheral haemorrhages, originally of some concern, resolved over a period of one to five weeks. All the detachments left a posterior pigment line, but in only one instance did the line invade the macula. In 
Table 4 Results: after cryotherapy

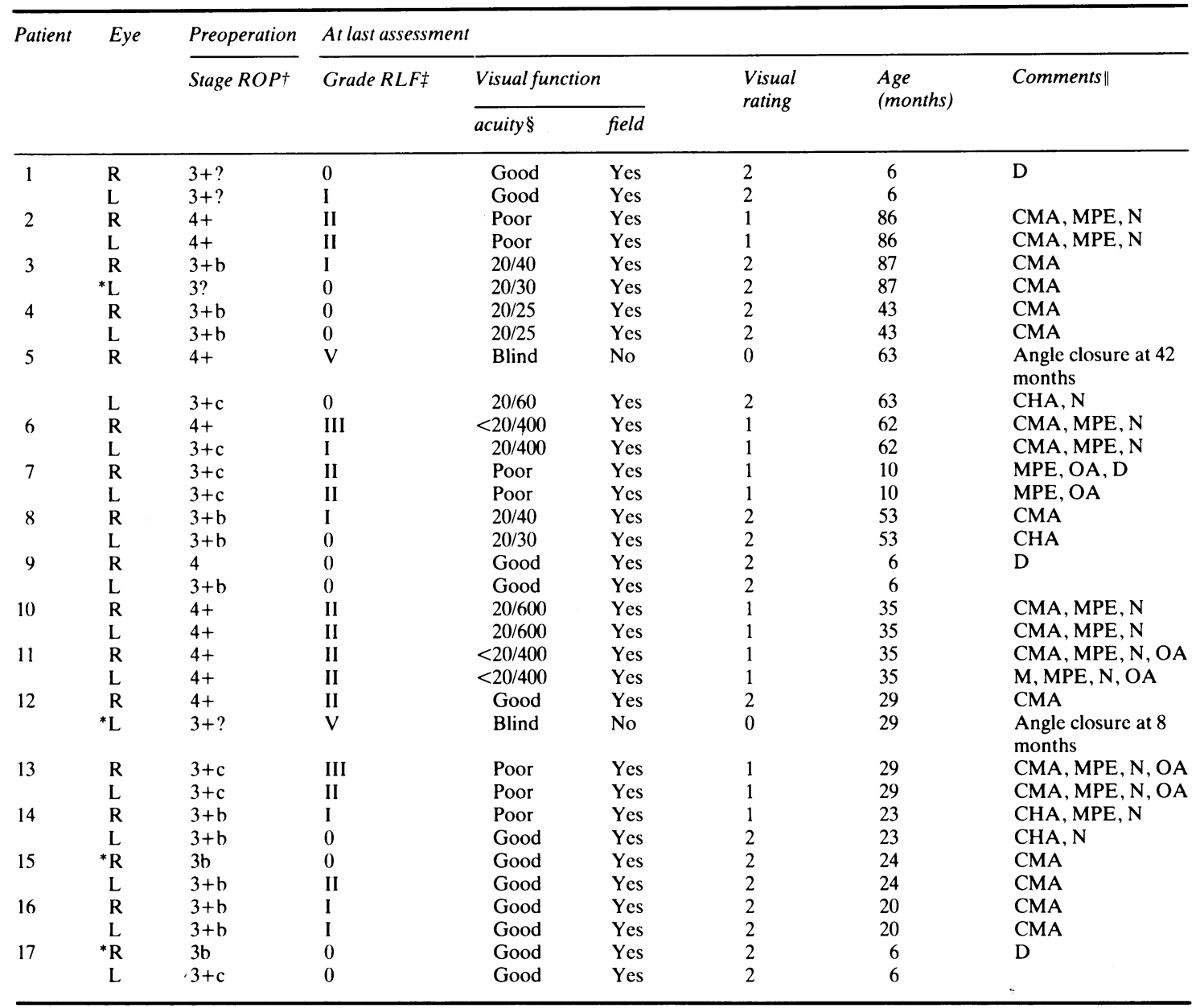

* Eye not treated.

+ ROP = retinopathy of prematurity; ? = substage of ROP not determinable.

$\ddagger$ RLF $=$ retrolental fibroplasia.

$\S$ Good: $20 / 60$ or better corrected acuity estimated; poor: less than 20/60 corrected acuity estimated.

\# $\mathrm{CHA}=$ Compound hyperopic astigmatism; $\mathrm{CMA}=$ compound myopic astigmatism; $\mathrm{D}=\mathrm{deceased} ; \mathrm{H}=\mathrm{hyperopia} ; \mathrm{M}=$ myopia $; \mathrm{MPE}=$ macular pigment epitheliopathy; $\mathrm{N}=$ nystagmus; $\mathrm{OA}=$ optic atrophy.

the right eye of patient 7 a new demarcation line (stage 1) appeared anterior to the cryotherapy and resolved spontaneously. One-half to one clock hour of stage $3+b$ retinopathy that had been missed between cryo spots usually resolved. However, if the disease progressed to stage $3+\mathrm{c}$ it was treated.

The long-term results are shown in Table 4. 'Grade O' retrolental fibroplasia has been used in the absence of cicatricial disease. Although these eyes had peripheral cryotherapy scars and posterior pole arterial tortuosity, the hallmark of past retinopathy, a grade of I seemed excessive.

A composite visual rating from 0 to 2 has been devised. In Denmark it has been determined that children with less than 20/60 corrected acuity are visually disabled. ${ }^{24} \mathrm{~A}$ rating of 2 means a corrected acuity of $20 / 60$ or better with a functional field. A rating of 1 means a functional field with acuity less than $20 / 60$, and a rating of 0 is a totally blind eye. When subjective evaluation of acuity was not possible, an estimate of visual function was made on the basis of morphological integrity of the posterior pole, central fixation, and the absence of nystagmus.

Macular pigment epitheliopathy and optic atrophy had an effect on visual acuity. Macular pigment epitheliopathy was present in all 13 eyes rated 1 . The 
serous effusion that can occur in eyes with severe retinopathy or a subtle serous detachment of the retina extending to the macula in stage 4 retinopathy may be primarily responsible for this epitheliopathy. Compression of these delicate eyes during treatment may have contributed to that macular pigment epitheliopathy. Its infrequency in those eyes treated with stage $3+b$ retinopathy is fairly reassuring. Optic atrophy was bilateral in all cases, and, in view of the other potential causes of optic atrophy in these infants, it is unlikely that it was caused by the application of cryotherapy. Nevertheless, prolonged compression of eyes during cryotherapy should be avoided.

\section{ANALYSIS OF RESULTS}

Tables 5 and 6 correlate the preoperative retinopathy of prematurity to the resulting retrolental fibroplasia and visual rating respectively.

From Table 5 the occurrence of grade II to $\mathrm{V}$ retrolental fibroplasia was significantly higher in stage $3+c$ treated group $\left(p=0.045^{*}\right)$ and in the stage

Table 5 Anatomical results of treatment of 30 eyes with stage 3+ retinopathy or worse

\begin{tabular}{llllllll}
\hline $\begin{array}{l}\text { Stage of } \\
\text { ROP at } \\
\text { treatment }\end{array}$ & Eyes & \multicolumn{7}{c}{ Grade of RLF after treatment } \\
\cline { 2 - 8 } & & 0 & $I$ & $I I$ & $I I I$ & $I V$ & $V$ \\
\hline $3+?$ & $\mathrm{n}=2$ & 1 & 1 & & & & \\
$3+\mathrm{b}$ & $\mathrm{n}=11$ & 5 & 5 & 1 & & & \\
$3+\mathrm{c}$ & $\mathrm{n}=7$ & 2 & 1 & 3 & 1 & & \\
4 & $\mathrm{n}=1$ & 1 & & 7 & 1 & & 1 \\
$4+$ & $\mathrm{n}=9$ & & & 7 & & & \\
\hline Total & $\mathrm{n}=30$ & 9 & 7 & 11 & 2 & 0 & 1 \\
\hline
\end{tabular}

? Could not determine substage from records.

Table 6 Visual rating of 30 eyes after treatment for severe $R O P$

\begin{tabular}{|c|c|c|c|c|c|c|}
\hline \multirow{2}{*}{$\begin{array}{l}\text { Worst stage } \\
\text { of ROP } \\
\text { treated }\end{array}$} & \multirow[t]{2}{*}{ Eyes } & \multicolumn{3}{|c|}{ Visual rating* } & \multicolumn{2}{|c|}{ Comments $\ddagger$} \\
\hline & & 2 & 1 & 0 & $M P E$ & $O A$ \\
\hline $3+? \dagger$ & $\mathrm{n}=2$ & 2 & & & & \\
\hline $3+b$ & $\mathrm{n}=11$ & 10 & 1 & & 1 & \\
\hline $3+c$ & $\mathrm{n}=7$ & 2 & 5 & & 5 & $2(2)$ \\
\hline 4 & $\mathrm{n}=1$ & 1 & & & & \\
\hline $4+$ & $\mathrm{n}=9$ & 1 & 7 & 1 & 7 & 2 \\
\hline Total & $\mathrm{n}=\mathbf{3 0}$ & 16 & 13 & 1 & 13 & $4(2)$ \\
\hline
\end{tabular}

* Visual rating: $2=$ corrected acuity $>20 / 60$ plus functional field; 1 $=$ corrected acuity $<20 / 60$ plus functional field; $0=$ totally blind eye.

$\dagger ?=$ Substage of $3+$ ROP indeterminable .

$\ddagger \mathrm{MPE}=$ macular pigment epitheliopathy. $\mathrm{OA}=$ optic atrophy.

()$=$ suspected optic atrophy.
$4-4+$ group $\left(p=0.006^{*}\right)$ than in the stage $3+b$ group of eyes. A comparison of stage $3+c$ group with the stage 4-4+ group showed no significant difference $\left(\mathrm{p}=0 \cdot 147^{*}\right)$.

From Table 6 the occurrence of visual disability (visual rating of 1 or 0 ) was significantly higher in the stage $3+c$ treated group $\left(p=0.013^{*}\right)$ and in the stage $4-4+$ group $(0.0005<\mathrm{p}<0.005 \dagger)$ than that which followed treatment of the stage $3+b$ group of eyes. Visual disability following treatment of the stage $3+c$ group compared with stage 4-4+ group was not significantly different $(0.3<p<0.4 \dagger)$.

The above analysis indicates that treatment of stage $3+b$ retinopathy of prematurity by the methods outlined produces significantly less retrolental fibroplasia and significantly better visual function than treating stage $3+c$ or stage 4-4+ disease. In addition stage $3+c$ and stage $4-4+$ retinopathy of prematurity are similar disease in terms of response to this treatment.

\section{Discussion}

There is a so far ill-defined critical mass of retinopathy of prematurity that will by natural progression result in loss of vision and significant retrolental fibroplasia. Any form of treatment, including its complications, must produce less visual disability and less RLF than the natural course of the disease.

The spontaneous resolution of stages 1 and 2 ROP without significant residual disease is most certainly the rule, and accordingly treatment of eyes reaching only these stages of disease is contraindicated. The success of treatment of selected cases of stage 3 disease or worse is affected by (1) the stage of ROP treated; (2) the method of treatment; (3) the location of treatment.

McCormick $^{25}$ has reported blindness and severe RLF in eyes that had any degree of retinal detachment or stage 4 ROP (12 of 14 eyes with grade V RLF and two with grade III RLF). Tasman ${ }^{26}$ and $\mathbf{Z a k}^{27}$ have recently re-emphasised the significance of retinal detachment in ROP. McPherson et al. ${ }^{15}$ reported anatomical success with scleral buckling and cryotherapy in $75 \%$ of cases with stage 4 ROP. In this series, in which we treated early serous retinal detachments just posterior to the ridge with cryotherapy only to the ridge and the extraretinal fibrovascular proliferation at the ridge, anatomical success was achieved in $80 \%$. However, only $20 \%$ escaped visual disability (corrected acuity of less than $20 / 60$ ). Treatment of stage 4 ROP is clearly indicated but does not eliminate visual disability and RLF grade II or worse.

Treatment of stage 3 ROP was first reported by 
Nagata et al. ${ }^{28}$ using photocoagulation. Nagata ${ }^{29}$ subsequently summarised 10 years of treatment. The borderline between avascular and vascular retina was the main target of photocoagulation. He stated that it did not seem essential to coagulate the proliferated vessels themselves. When present, a wide avascular area was also treated with random spots. Visual and anatomical (less than grade II RLF) success was accomplished in $95 \%$ of cases, but $21.8 \%$ of infants weighing $1500 \mathrm{~g}$ or less at birth were treated. He estimated that only $20 \%$ of those treated might have gone on to severe RLF if not treated. However, he also suggested that it may be reasonable to treat all cases which have any possibility of developing grade II RLF or worse.

Majima et al. treated with photocoagulation middle stage 3 in 12 eyes and watched the untreated fellow eyes. ${ }^{31}$ Two progressed to late stage 3 and were treated successfully. The remaining 10 resolved with RLF grade I.

Ben Sira et al. " treated $16 \%$ of eyes with any ROP in infants under $1500 \mathrm{~g}$ birth weight $(32 \%$ of eyes with ROP in infants under $1000 \mathrm{~g}$ and $13 \%$ of eyes with ROP in infants from 1000 to $1500 \mathrm{~g}$ birth weight). They applied cryotherapy to the avascular retina without particular attempt to freeze the neovascular tufts. Fourteen of 18 eyes $(78 \%)$ had RLF grade I or less. None were worse than grade II RLF. Their description of the ROP treated conforms to middle or moderate stage $3 \mathrm{ROP}$ as in the International Classification and as qualified earlier in this report.

In this report $7 \cdot 5 \%$ of all eyes with any ROP in infants under $1500 \mathrm{~g}$ birth weight were treated $(12.5 \%$ in infants under $1000 \mathrm{~g}$ and $3.5 \%$ in infants 1000 to $1500 \mathrm{~g}$ birth weight). The eyes had middle or moderate stage 3 'plus' ROP or worse and the ridge extraretinal fibrovascular proliferative complex was treated with cryotherapy. No attempt was made to treat posterior extensions of extraretinal fibrovascular proliferation beyond the cryo spot that straddled the ridge. Of the middle stage 3 'plus' ROP treated eyes, 10 of 11 eyes $(91 \%)$ had less than grade II RLF and no visual disability. The one visually disabled eye had grade II RLF. Of all the stage 3 'plus' eyes treated, 15 of $20(75 \%)$ had less than grade II RLF and 14 of 20 (70\%) had no visual disability. No eyes were completely blind, and only one eye had worse than grade II RLF.

We conclude that: (1) Treatment of ROP does reduce RLF and visual disability. (2) Stage 4 ROP is a clear indication for treatment; scleral buckling and cryotherapy are probably necessary for advanced detachments; cryotherapy alone may succeed with early detachments just posterior to the ridge. (3) Late or severe stage 3 ROP can be treated with cryotherapy or photocoagulation, but the elimination of visual disability and ocular morbidity is unlikely. (4) The treatment of selected progressive cases of middle or moderate stage 3 'plus' ROP can achieve the goals of therapy. It must be emphasised that only selected progressive cases of stage 3 'plus' ROP should be treated, with 'plus' disease being the major criterion for selection. (5) Several methods of treatment and locations of treatment appear to be effective.

Accordingly our attention should be directed to the improvement of diagnostic methods and documentation and to the comparison of methods and locations of treatment. In addition it is fundamental that the International Classification of Retinopathy of Prematurity be adopted as the sole standard of communication to enable critical analysis and peer review.

\section{${ }^{*}$ Fisher's exact test. \\ $+\chi^{2}$ with 2 degrees of freedom}

A W Rademaker, PhD, Department of Community Health Science, Faculty of Medicine, University of Calgary, did the statistical analysis.

This work was supported by the Alberta Children's Hospital Foundation.

\section{References}

1 Phelps DL. Retinopathy of prematurity: an estimate of vision loss in the United States, 1979. Pediatrics 1981; 67: 924.

2 Hittner HM, Kretzer FL. Vitamin E and retrolental fibroplasia: ultrastructural mechanism of clinical efficacy. In: Diplock AT, Porter R, eds. Ciba Foundation Symposium 101. Biology of vitamin E. London: Pitman, 1983: 165-82.

3 Finer NN, Schindler RF, Peters KL, Grant GD. Effect of intramuscular Vitamin E on frequency and severity of retrolental fibroplasia. A control trial. Lancet 1982; i: 1087-91.

4 Puklin JE, Simon RM, Ehrenkranz RA. Influence on retrolental fibroplasia of intramuscular vitamin $\mathrm{E}$ administration during respiratory distress syndrome. Ophthalmology (Rochester) 1982; 89: $96-103$

5 Johnson L, Schaffer D, Ouinn G. Vitamin E supplementation and the retinopathy of prematurity. Ann NY Acad Sci 1982; 393: 473-95.

6 Uemura Y. Current status of retrolental fibroplasia: report of the Joint Committee for the Study of Retrolental Fibroplasia in Japan. Jpn J Ophthalmol 1977; 21: 366-78.

7 Hindle NW, Leyton J. Prevention of cicatricial retrolental fibroplasia by cryotherapy. Can J Ophthalmol 1978; 13: 277-82.

8 Yassur Y, Grunwald E, Ben Sira I. Surgical treatment of retrolental fibroplasia in infants. Metab Ophthalmol 1978; 2: $333-4$.

9 Koerner FH. Retinopathy of prematurity. Natural course and management. Metab Ophthalmol 1978; 2: 325-9.

10 McPherson A, Hittner HM. Scleral buckling in $2 \frac{1}{2}$ to 11 month old premature infants with retinal detachment associated with acute retrolental fibroplasia. Ophthalmology (Rochester) 1979; 86: 819-36.

11 Ben Sira I, Nissenkorn I, Grunwald E, Yassur Y. Treatment of acute retrolental fibroplasia by cryopexy. Br J Ophthalmol 1980; 64: $758-62$.

12 Mousel DK, Hoyt CS. Cryotherapy for retinopathy of prematurity. Ophthalmology (Rochester) 1980; 87: 1121-7. 
13 Bert MD, Friedman MW, Ballard R. Combined cryosurgery and scleral buckling in acute proliferative retrolental fibroplasia. $J$ Pediatr Ophthalmol Strabismus 1981; 18: 9-11.

14 Hindle NW. Cryotherapy for retinopathy of prematurity to prevent retrolental fibroplasia. Can J Ophthalmol 1982; 17: 207-12.

15 McPherson AR, Hittner MH, Lemos R. Retinal detachment in young premature infants with acute retrolental fibroplasia. 32 new cases. Ophthalmology (Rochester) 1982; 89: 1160-9.

16 Stark DJ, Manning LM, Lenton L. The incidence and results of active treatment of acute retrolental fibroplasia. Aust $J$ Ophthalmol 1982; 10: 1935

17 Harris GS, McCormick AQ. The prophylactic treatment of retrolental fibroplasia. Mod Probl Ophthalmol 1977; 18: 364-67.

18 Keith CG. Visual outcome and effect of treatment in stage III developing retrolental fibroplasia. $\mathrm{Br} J$ Ophthalmol 1982; 66: 446-9.

19 Kingham JD. Acute retrolental fibroplasia. II. Treatment by cryosurgery. Arch Ophthalmol 1978; 96: 2049-53.

20 An international classification of retinopathy of prematurity. $\mathrm{Br}$ J Ophthalmol 1984; 68: 690-7.

21 Owens WC. Symposium: Retrolental fibroplasia (retinopathy of prematurity). Clinical course. Am J Ophthalmol 1953; 40: 159-62.
22 Hindle NW. International classification of retrolental fibroplasia: a proposal. Can J Ophthalmol 1982; 17: 107-9.

23 Hindle NW. The Calgary Code: a numerical and alphabetical nosography of retrolental fibroplasia. Can J Ophthalmol 1982; 17: 110-2.

24 Fledelius H. Prematurity and the eye. Copenhagen: Trykteknik, 1976: 117.

25 McCormick AQ. Retinopathy of prematurity. Curr Probl Pediatr 1977; 7: 1-28.

26 Tasman W. The natural history of active retinopathy of prematurity. Ophthalmology (Rochester) 1984; 91: 1499-1502.

27 Zak T. Discussion. Ophthalmology (Rochester) 1984; 91: 1502-3.

28 Nagata M, Kobayashi Y, Fukuda H, Suckane K. Photocoagulation for the treatment of retinopathy of prematurity. Jpn J Clin Ophthalmol 1968; 22: 419-27.

29 Nagata M. Treatment of acute proliferative retrolental fibroplasia with xenon-arc photocoagulation: its indications and limitations. Jpn J Clin Ophthalmol 1977; 21: 436-59.

30 Majima A, Takahashi M, Hibino Y, Kamao N, Takai M. Clinical observation of photocoagulation on retinopathy of prematurity. Jpn J Clin Ophthalmol 1976; 30: 93-7.

Accepted for publication 19 July 1985. 